\title{
TOMÁS NAVARRO TOMÁS Y LOS ORÍGENES DE LA FONÉTICA EXPERIMENTAL EN LA JAE
}

\author{
José M. Sánchez Ron
}

Universidad Autónoma de Madrid

\section{RESUMEN}

La introducción en España de la fonética experimental, una rama de la lingüística fronteriza con las ciencias, tuvo como uno de sus principales protagonistas a Tomás Navarro Tomás, que dirigió un Laboratorio de Fonética en el Centro de Estudios Históricos de la Junta para Ampliación de Estudios. En este artículo se reconstruye una parte esencial de la formación de Navarro Tomás en ese campo, utilizando para ello las cartas que envió a Ramón Menéndez Pidal mientras estuvo pensionado en el extranjero (Francia y Alemania) por la Junta en 1912-1913. Se trata de una correspondencia que, además, presenta una excelente visión de la comunidad fonética europea de la época.

PALABRAS CLAVE: Tomás Navarro Tomás. Ramón Menéndez Pidal. Fonética experimental. Fonética en Francia y Alemania (1912-1913). Centro de Estudios Históricos. Junta para Ampliación de Estudios. Centro de Estudios Históricos. Pensiones.

\section{TOMÁS NAVARRO TOMÁS AND THE ORIGINS OF EXPERIMENTAL PHONETICS AT THE JAE}

\begin{abstract}
The introduction in Spain of experimental phonetics, a branch of linguistic close to science, had as one of its main protagonists Tomás Navarro Tomás, who was the director of a Laboratory of Phonetics at the Historical Studies Center of the Junta para Ampliación de Estudios. In this article, we study Navarro Tomás's education in that field, making use of the letters he sent to Ramón Menéndez Pidal while he was abroad (France and Germany) supported by the Junta in 1912-1913. Besides, that correspondence presents an splendid view of the European phonetic community of the time.
\end{abstract}

KEY WORDS: Tomás Navarro Tomás. Ramón Menéndez Pidal. Experimental phonetics. Phonetics in France and Germany (1912-1913). Junta para Ampliación de Estudios. Historical Studies Center. Grants.

La historia de la Junta para Ampliación de Estudios e Investigaciones Científicas (JAE) está repleta de nombres destacados de la cultura española: 
Santiago Ramón y Cajal, Ramón Menéndez Pidal, Blas Cabrera, Américo Castro, Leonardo Torres Quevedo, Ignacio Bolívar, Enrique Moles, Rafael Lapesa, Julio Rey Pastor, Dámaso Alonso, Miguel Catalán, y un largo etcétera. Un nombre acaso menos conocido para algunos sea el de Tomás Navarro Tomás (1884-1979); sin embargo, y dejando al lado por un momento sus contribuciones a la lingüística (a la fonética en particular), pocos pueden presumir de una relación tan continuada con la Junta como la que mantuvo él. Así, si consultamos la primera memoria preparada por la JAE, la correspondiente a 1907, el año en que fue creada, nos encontramos no sólo con que Navarro Tomás - también conocido por las singulares siglas de su nombre y apellidos, TNT - recibió una de las pensiones concedidas ${ }^{1}$, sino que también contribuyó a esa memoria con un trabajo, uno de los cuatro apéndices incluidos, en el que en 22 páginas describía su «Pensión al Alto Aragón»². Por otra parte, continuó sirviendo a la Junta durante la Guerra Civil, cuando no eran muchos los que permanecían activos en

1 Esto es lo que se lee en la Memoria: «Una subvención de 1.022 pesetas a D. Tomás Navarro Tomás, Doctor en Filosofía y Letras, para realizar estudios filológicos por tres meses en Huesca, Jaca y localidades siguientes hasta Boltaña. Este aspirante había presentado una serie de trabajos, producto de dos años de labor asidua, consistentes en documentos copiados, según el dictamen del Ponente, con todo el rigor paleográfico apetecible, indicando con letras subrayadas todas las abreviaturas disueltas, manteniendo escrupulosamente la ortografía y separación de palabras del original, y salvando por medio de notas todas las dificultades de lectura, de tal modo, que esos documentos así copiados, se prestan a un estudio filológico seguro. Presentó, además, gran número de papeletas de gramática y vocabulario referentes a esos mismos documentos, hechas con perfecto conocimiento del método filológico. También este aspirante había hecho prácticas con el Ponente Sr. Menéndez Pidal». Y más adelante, tras mencionar algunas de las circunstancias que se dieron durante su trabajo, se añadía: «A su regreso presentó a la Junta una colección de cien documentos de gran valor histórico y filológico, sacados de los archivos municipales, eclesiásticos y notariales de todo el Alto Aragón, acompañados de 4.000 células de vocabulario antiguo e ilustrados con multitud de observaciones sobre el dialecto moderno».

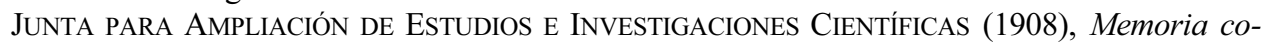
rrespondiente al año 1907, Madrid, pp. 37-38. La memoria que Navarro Tomás presentó a la JAE al solicitar la pensión anterior se reproduce en SALABERRIA, R. (ed.) (2007), Tomás Navarro Tomás, ciudadano TNT, Toledo, Servicio de Publicaciones. Consejería de Cultura de Castilla-La Mancha, pp. 31-35.

2 Los autores de los tres restantes fueron: Agustín Blánquez Fraile («Límites del dialecto leonés occidental en Alcañices, Puebla de Sanabria y La Bañeza»), Santiago Ramón y Cajal («Memoria presentada por D. S. Ramón y Cajal, delegado oficial en el Congreso Internacional de Neuro-psichiatría, Psicología y asistencia de alienados, celebrado en Amsterdam durante el mes de Septiembre de este año») y José Gómez Ocaña («Memoria que elevan a la Junta de Investigaciones Científicas los delegados de España en el VII Congreso Internacional de Fisiólogos, celebrado en Heidelberg en agosto de 1907»). 
ella (Blas Cabrera, por ejemplo, había abandonado España en fecha tan temprana con septiembre de 1936 y Ramón Menéndez Pidal poco después, a finales de año). Evidencia en este sentido es la carta que Navarro envió el 21 de enero de 1937, desde Valencia, a Menéndez Pidal. Es interesante citarla no sólo como evidencia de la dilatada relación de Navarro Tomás con la JAE sino también porque en ella habla de algunos aspectos de la vida de los intelectuales que se instalaron a Valencia cuando el gobierno de la República trasladó su sede a Valencia ${ }^{3}$ :

«Querido don Ramón: Desde hace varias semanas me encuentro en Valencia con mi mujer y mis hijas. Vivo en la residencia que el Ministerio ha improvisado para los intelectuales evacuados de Madrid. Nos encontramos bien y satisfechos dentro de las graves preocupaciones que cada uno lleva dentro. El Ministerio y especialmente Rocer tiene toda clase de atenciones con nosotros procurando rodearnos de facilidades para trabajar y hasta de cuidados familiares.

Vamos a publicar unos cuadernos con la colaboración de los que convivimos en la Casa de la Cultura. ${ }^{4}$ El título de la Casa, aunque resulta pedante, hay que soportarlo. Los cuadernos, con trabajos tan dispares, no tendrán el carácter de una revista normal. Serán la expresión bibliográfica de las circunstancias extraordinarias que han reunido bajo un mismo techo a este grupo de gentes.

Me ocupo mucho de llevar adelante los asuntos de la Junta procurando que no se extingan los trabajos que puedan continuar y que no queden abandonadas las gentes que han sido útiles y puedan volver a serlo. El Ministerio muestra decidido interés en mantener nuestras actividades. Como yo solo no podía autorizar ciertas resoluciones propuse la formación de una comisión interina con elementos que se encontrasen en Valencia. El Ministerio aprobó la propuesta designando para presidente al Dr. Márquez y para vocales a Moreno Villa y Victorio Macho.

Hemos salvado el cuaderno de la Revista de Filología Española que había quedado en la encuadernación de la Imprenta de Hernando. Vamos a hacer su reparto en estos días. Además estamos preparando otro cuaderno que se va a componer en

3 Depositada en la Fundación Ramón Menéndez Pidal (Madrid), al igual que las demás cartas que se utilizan en este artículo. Agradezco a Diego Catalán que me permitiese consultar - en tiempos tan difíciles para la institución que dirige - los documentos depositados en ella.

4 La Casa de la Cultura se inauguró oficialmente, instalada en el Hotel Palace de Valencia, el 11 de diciembre de 1936. Tras una crisis, provocada por unas manifestaciones de Gonzalo Rodríguez Lafora, el 12 de agosto de 1937 comenzó una segunda etapa de la Casa, quedando constituido un patronato dirigido por Antonio Machado e integrado por Manuel Márquez, Victorio Macho, José Moreno Villa y el propio Tomás Navarro Tomás como vocales, y Luis Álvarez Santullano de secretario. Véase AzNAR Soler, M. (1987), II Congreso Internacional de Escritores para la Defensa de la Cultura (1937). Literatura española y antifascismo (1927-1939), Valencia, Generalitat Valenciana, pp. 99-100. 
Valencia. Están aquí Montesinos y Dámaso Alonso y aun cuando carezcamos de muchos elementos nos esforzamos en mantener la continuidad de la Revista. La normalidad en Valencia es completa y se podría trabajar si tuviéramos aquí los materiales del Centro.

Hemos traído también a Valencia a Pronfante para que se ocupe de la continuación de Emérita. Lapesa no ha querido salir de Madrid, por motivos familiares que le impiden moverse de allí. La FETE [Federación Española de Trabajadores de la Enseñanza] le ha encargado la guardia y custodia del Centro. Me dice que han bajado a los sótanos todos los manuscritos de usted, los ficheros del Glosario y Corpus, los ficheros de la Sección de Arte y los aparatos de fonética. Los cuadernos del Atlas me los trajo a Valencia el $5^{\circ}$ Regimiento. Creo que Gili Gaya va a venir también, incorporado al Instituto Escuela de Valencia.

Aparte de mi colaboración a la revista de la Casa de la Cultura, voy a dar un cursillo de fonética en la Universidad y voy a tomar parte en una serie de conferencias que los compañeros de residencia estamos organizando. Tengo además a mi cargo los asuntos del Cuerpo de Archivos y aún me queda tiempo para seguir un curso de ruso y aprender declinaciones y conjugaciones.

Para ayudarme en la Secretaría de la Junta están aquí Fernández y uno de sus auxiliares. También está Santullano, pero lo han agregado a la inspección de escuelas y ha cesado como vicesecretario.

Me gustará tener noticias de usted y de su familia.

Suyo, T. Navarro Tomás»»

Pero no es de esto de lo que trata el presente artículo, de cuánto tiempo Navarro Tomás trabajó en la JAE, o si lo hizo más o menos que otros, sino de sus primeros años de investigador; más concretamente del período que pasó pensionado por la Junta en Francia y Alemania. Fue entonces cuando se formó en una rama de la lingüística fronteriza como pocas con las ciencias naturales, con la física, fisiología y anatomía en particular: la fonética experimental. Utilizando documentos depositados en la Fundación Menéndez Pidal citaré extensamente de las cartas que Navarro Tomás escribió a su maestro, Ramón Menéndez Pidal, informándole de sus progresos y de todo lo que veía. Fragmentos de algunas de estas cartas han sido citados anteriormente, pero nunca con la extensión que se hace aquí, ni, en general, teniendo como horizonte únicamente la fonética experimental. ${ }^{5} \mathrm{El}$ incluirlos y analizarlos aquí, en una revista de historia de la ciencia, constituye, en mi opinión, una buena manera de aproximar las humanidades y las ciencias, en un apartado especialmente adecuado.

5 PÉrez PAscuAl, J.I. (2000), «Algunas notas sobre la prehistoria del Atlas Lingüístico de la Península Ibérica», en Lengua y discurso. Estudios dedicados al profesor Vidal Lamíquiz, Madrid, Arco Libros, pp. 751-760; y Pedrazuela Fuentes, M. (2005), «Nuevos Documentos para la historia del ALPI», Revista de Filología Española 85, 271-293. 


\section{TOMÁS NAVARRO TOMÁS}

Tomás Navarro Tomás nació en La Roda de la Mancha, el 12 de abril de 1884 y murió, exiliado de su patria como consecuencia de la Guerra Civil (en la que ocupó el distinguido cargo de Director de la Biblioteca Nacional), en 1979 en Northampton (Estados Unidos).

Había comenzado sus estudios universitarios, la carrera de Filosofía y Letras, en Valencia, aunque la terminó en la Universidad de Madrid, en la que también se doctoró. En la capital entró en contacto con Ramón Menéndez Pidal, al que estaría ligada su carrera como investigador mientras permaneció en España. En este sentido, en su discurso de entrada a la Real Academia Española (19 de mayo de 1935) manifestó6:

«Se hallan entre vosotros don Miguel Asín, de quien recibí estímulos inolvidables al principio de mis estudios, y don Ramón Menéndez Pidal, a quien debo la orientación definitiva de mi vocación, la instrucción en la rigurosa disciplina de sus enseñanzas y el consejo generoso que ha guiado en todo momento mi trabajo.

Al dedicar mi atención al estudio de la fonética española como base indispensable para la elaboración del Atlas Lingüístico de nuestro país, mi inclinación fue guiada por el plan de conjunto sobre el cual el señor Menéndez Pidal organizó el programa de la Sección de Filología del Centro de Estudios Históricos».

Alonso Zamora Vicente, el último discípulo español de Navarro Tomás, se refirió también a los inicios de la relación de su maestro con Menéndez Pidal en los términos siguientes ${ }^{7}$ :

6 Navarro Tomás, T. (1935), El acento castellano, Madrid, Tipografía de Archivos, pp. 7-8. Otro de los discípulos de Menéndez Pidal de aquella época, Javier Sánchez Cantón, escribió, recordando el curso de doctorado del curso 1910-1911, al que asistió como alumno: «De las tres clases semanales, teníamos dos en el edificio de la calle de San Bernardo (...), mientras la tercera se daba en la Sección de Filología del inolvidable Centro de Estudios Históricos, recién instalado — es un decir - en el bajo del Palacio de Bibliotecas y Museos (...). En torno de una mesa de barnizado pino, sobre suelo de cemento, nos sentábamos en duras, incómodas e iguales sillas don Ramón, los alumnos y varios colaboradores; recuerdo a Navarro Tomás, a Américo Castro (...). Las clases (...) transcurrían sin el menor engolamiento. Sobre cualquier punto hablaba el que tuviese algo que decir, o quien creyese que podía decir cosa aprovechable». SÁNCHEZ CANTÓN, J. (1959), «La lección de su sencillez», $A B C, 19$ de marzo; citada en PÉREZ PASCUAL, J.I. (1998), Ramón Menéndez Pidal. Ciencia y pasión, Valladolid, Junta de Castilla y León, p. 125. Véase, asimismo, Navarro Tomás, T. (1968-1969), «Don Ramón Menéndez Pidal en el Centro de Estudios Históricos», Anuario de Letras VII, pp. 9-24.

7 ZAMORA ViCENTE, A. (2001), «En recuerdo de Tomás Navarro Tomás», en Los orígenes de la fonética experimental en España, Cáceres, Fundación Biblioteca Alonso Zamora Vicente, pp. 19-27; p. 20. 
«Don Ramón Menéndez Pidal supo escoger con acierto a sus colaboradores y repartirlos por los campos más necesitados de conocimiento. En estos años primerizos, 1909-1914, Tomás Navarro Tomás, Américo Castro, A[ntonio] [García] Solalinde, Federico de Onís, José Fdez. Montesinos (y algunos más, dispersos luego por diversas razones, incluso por la inesperada muerte de alguno) comenzaron las tareas. Se empezó el estudio de los documentos antiguos, revisando y recorriendo archivos, ya regios o eclesiásticos, ya privados; se ordenó el estudio de los Fueros medievales, se revisaron viejas fronteras lingüísticas; comenzamos a disponer de ediciones fiables de los viejos textos, hechas con rigor y sabiduría y no sometidas a la dictadura casi única de la historiografía o del estilo oratorio y hueco. Se tradujeron libros capitales para el estudioso hispano. Todo estaba por hacer; sobre todo faltaba una norma acatada que impusiera un método parejo al empleado en Europa y que, sin ser pregonado a tambor batiente, fuera considerado norma de universal validez».

De hecho, la influencia de Menéndez Pidal en los trabajos de TNT comenzó al menos en las Navidades de 1905, cuando éste recogió en su ciudad natal, La Roda, catorce versiones de romances, como parte del afán de su maestro por preparar un gran Romancero ${ }^{8}$.

En lugar de optar por la carrera universitaria, Navarro Tomás optó por el Cuerpo de Archiveros, Bibliotecarios y Arqueólogos, en el que pronto ganó plaza como Jefe de Archivo de Hacienda de la provincia de Ávila, desde donde pronto se trasladó al Archivo Histórico Nacional.

Instalado en Ávila, el 6 de abril de 1910, solicitó una nueva pensión de la JAE. Es interesante citar algunos pasajes de la solicitud que presentó ${ }^{9}$ :

«D. Tomás Navarro Tomás, natural de La Roda, provincia de Albacete, Doctor en Letras, Oficial de $4^{\circ}$ grado del Cuerpo facultativo de Archiveros, Bibliotecarios y Arqueólogos, jefe del Archivo de Hacienda de la provincia de Ávila (...), respetuosamente expone:

Que desde hace bastante tiempo ha venido dedicando la mayor parte de su atención al estudio de la filología española y en especial al de los dialectos de nuestra nación, como base y fundamento para ulteriores estudios generales acerca de nuestra literatura y nuestro idioma; pero que siendo en estas materias, por lo que a nuestro país se refiere, muy escasas las noticias publicadas, y casi desconocidos los límites y relaciones de nuestras hablas regionales, el exponente ha comprendido la absoluta necesidad de acudir personalmente a los lugares en que esas hablas se

8 Sobre este punto, véase CAtalán, D. (2001), El Archivo del Romancero, Patrimonio de la Humanidad, Madrid, tomo I, p. 47.

9 Archivo de la Junta para Ampliación de Estudios, Residencia de Estudiantes, Madrid. Citada en SAlaberria (ed.) (2007), pp. 37-38. 
conservan para poder conocerlas y determinarlas. Las antiguas documentaciones de los Archivos, cuyo estudio tanto ilustra la historia de nuestro idioma, tienen su complemento en estas investigaciones sobre la extensión, naturaleza y límites de estos preciosos restos del viejo romance que, afortunadamente aún pueden ser sorprendidos en muchos pueblos; pues si por los documentos puede conocerse la índole y carácter de un dialecto, pocas veces basta su testimonio para deducir de ellos de una manera precisa las fronteras en que tal dialecto estuvo contenido; para esto es preciso acudir hoy al terreno en que existió, y por la situación geográfica del lenguaje actual, averiguar la suerte y vicisitudes porque han atravesado aquellos caracteres que en los antiguos documentos se manifiestan».

Para «resolver algunas cuestiones de esta naturaleza, relacionadas con el lenguaje vulgar de los partidos judiciales de Astorga, Ponferrada y Murias de Paredes, de la provincia de León», Navarro Tomás solicitaba una pensión de tres meses. En el apartado económico, lo que pedía eran 200 pesetas mensuales, «aparte del importe del viaje de ida y vuelta en ferrocarril y de los que necesite hacer de pueblo a pueblo en diligencia y caballería».

La pensión le fue concedida, y en la Fundación Menéndez Pidal sobreviven algunas cartas que envió a don Ramón. En una de las primeras, escrita desde Alcañices el 28 de agosto (1910), y al mismo tiempo que mencionaba algunos de sus hallazgos fonéticos, se refería a problemas económicos que le surgían y que merece la pena citar ya que no parece que fueran únicos entre los pensionados de la JAE:

«Antes de llegar a Alcañices escribí al habilitado de la Junta pidiéndole que me librase la segunda mensualidad a esta población, para cobrar a mi paso y continuar hacia la Puebla. Esto fue antes del 20 y no he tenido más contestación sobre ese asunto que la tarjeta [de Domingo Barnés] recibida hoy mismo, salida de Madrid el 16, según el sello de correos. Barnés me dice que entregó mi carta al Sr. Estevan con el consiguiente interés, pero no me dice nada sobre el envío de fondos con la rapidez que yo los necesito, antes parece deducirse lo contrario de lo que me recomienda de 'tener paciencia por ahora, y cuando volvamos se verá cómo pueden corregirse estas deficiencias'...

Mi pensión comenzó en 22 de Junio, hace más de dos meses, y hasta la fecha aún no se me han entregado más que 338 pesetas. Llevo gastadas 460 y me quedan en el bolsillo unas 60 más; con esto no puedo continuar a Sanabria, ni puedo hacer otra cosa más que esperar unos días hasta ver si me mandan lo de la segunda mensualidad».

Poco antes de que Navarro Tomás solicitase la pensión a la que me he referido, por un Real Decreto de 18 de marzo (1910) se creó el Centro de Estudios Históricos, en el que se desarrollaría su labor investigadora, a cuya cabe- 
za se puso a Menéndez Pidal ${ }^{10}$. Una de las subsecciones del Centro era un Laboratorio de Fonética, que comenzó a funcionar desde 1910-1911, dirigido por Navarro Tomás auxiliado por Gili Gaya, aunque en realidad hasta 1916 no se constituyó como un departamento plenamente establecido.

Las investigaciones que Navarro Tomás estaba llevando a cabo aquellos primeros años se basaban, fundamentalmente, en encuestas de campo o trabajos de archivo. Pero se debió dar cuenta de que el análisis del habla, de la pronunciación, de, en definitiva, la fonética requería de los medios técnicos a los que la tecnología contemporánea ya permitía acceder; esto es, que necesitaba de una fonética verdaderamente experimental. Por supuesto, no fue el primero en darse cuenta de esto.

\section{PRIMEROS PASOS DE LA FONÉTICA EXPERIMENTAL EN ESPAÑA}

Un instrumento para recoger y conservar el sonido, el, como se le denominó, fonógrafo, había sido inventado por Edison en 1877. Aquel primer modelo registraba los sonidos en hojas de papel de estaño (también, parece, de papel parafinado). Ya en las primeras pruebas, «recitaron y cantaron, probando repetidamente las voces de cada uno y escuchando luego la reproducción reiterada de sus palabras» ${ }^{11}$. El aparato original se hacía girar a mano, y el cilindro avanzaba lenta y longitudinalmente mediante una tuerca que giraba sobre la rosca del árbol del cilindro, que estaba recubierto por una hoja de papel de estaño, que se ponía en contacto con una aguja registradora de perfil semejante al de un cincel y que se hallaba unida al centro de un diafragma de hierro.

Aproximadamente una década más tarde, ya libre de sus trabajos con la lámpara incandescente, Edison abandonó el papel de estaño por cilindros de

10 La primera sede del Centro estuvo situada en unas grandes y mal acondicionadas salas de la planta baja del edificio de la Biblioteca Nacional, ocupadas anteriormente por el Museo de Ciencias Naturales, donde habilitaron una serie de despachos con tabiques de madera que, a causa de los altos techos, no llegaban más que a media altura. Sobre el Centro de Estudios Históricos, véase José MARÍA LóPEZ SÁnCHEZ (2006), Heterodoxos españoles. El Centro de Estudios Históricos, 1910-1936, Madrid, Marcial Pons. Es útil, asimismo, ABAD, F. (1988), «La obra filológica del Centro de Estudios Históricos», en SÁNCHEZ RoN. J.M. (coord..) (1988), 1907-1987. La Junta para Ampliación de Estudios e Investigaciones Científicas 80 años después, Madrid, Consejo Superior de Investigaciones Científicas, vol. II, pp. 503-517.

11 FRANK LEWIS DYER y THOMAS COMMERFORS MARTIN con la colaboración de WILLIAM HENRY MEAdOWCROFT (1933), Edison, su vida y sus inventos, Barcelona, Editorial Araluce (edición original en inglés de 1929), p. 154. 
cera, en los cuales la impresión también se formaba con un cincel. Tal registro, o fonograma, como fue llamado, podía ser separado del aparato o ponerlo nuevamente en él, sin destruir la impresión y de esta manera obtener muchas reproducciones sin alterarla. Cuando se deseaba, era posible también tornear el cilindro a fin de borrar lo impreso y dejar una superficie absolutamente lisa y en condiciones de hacer una nueva impresión. Hasta 1893, Edison obtuvo 65 patentes relacionadas con el fonógrafo, aunque su modelo básicamente final quedó establecido en 1889.

Al menos desde 1904 Menéndez Pidal utilizó un fonógrafo de cilindro de cera. Así, en la «Dedicade» que el medievalista e hispanista francés Jean Ducamin hacía a Menéndez Pidal en su edición en gascón de la Disciplina clericalis del judío converso español Pedro Alfonso (Pierre Alphonse, Disciplines de clergie et de moralités; 1908) recordaba que durante las vacaciones que había pasado en agosto de 1904 en El Paular escuchó la voz de la hija de don Ramón, Jimena (que entonces tenía tres años), grabada en un fonógrafo de cilindro de cera, y cantando el romance de «Don Bueso» ${ }^{12}$.

El 24 de diciembre de aquel mismo año, María Goyri escribía a su marido, que en aquel momento viajaba a la Argentina: «A estas horas (101/2) ya estarás en alta mar y acaso mareado (...). Ya me han traído la caja del fonógrafo y ha quedado muy bien con su tapa con una pestaña por tres lados que ajusta muy bien. También tengo el grabador. Ahora sólo falta que García Plata mande a buscarlo». La idea era que Rafael García Plata, uno de los colectores de romances que colaboraba con Menéndez Pidal, lo utilizara en Alcuéscar, donde vivía, pero este desinteresado colaborador no pudo enviar por el fonógrafo y pidió a Goyri si se lo podía enviar. Y el 3 de enero de 1905 lo embaló y envió a Extremadura. Como ha escrito Diego Catalán: «Cuando llegó el aparato de Alcuéscar, causó gran conmoción». Doña María informó a su marido: «Le envié un cilindro impresionado y dice que en cuanto recibieron el fonógrafo lo puso y que su señora se reía mucho y sus chicos fueron corriendo a llamar a los abuelos para que oyeran la 'máquina cantadora' En fin que está loco con el fonógrafo. Veremos lo que resulta. Me he gastado en caja, envío y cilindros 17 pts.»

Un mes más tarde, el 1 de febrero, María Goyri contaba a Menéndez Pidal: «Esta mañana vino el médico de Alcuéscar con una carta de García Plata pidiéndome otros cuatro cilindros (...). Se conoce que García Plata va a recoger tantas tonadas como letras. Veremos lo que dice luego Manrique de Lara [que transcribía las grabaciones]. Le he enviado seis cilindros para que no quede

12 Sobre estos puntos, véase CATALÁn (2001), tomo I, pp. 26, 41. 
por peseta más o menos, y porque eso hubieras hecho tú. Según me ha dicho el médico no hacen García Plata y su mujer más que aprender tonadas para impresionar cilindros». Más tarde, el 17 de mayo Menéndez Pidal compró otro fonógrafo, éste a «La fonográfica madrileña».

El propio Navarro Tomás se refirió a estos puntos en el estudio introductorio que incluyó, años más tarde (1931), en la memoria en la que presentaba los trabajos que se habían realizado en el Archivo de la Palabra, un proyecto que no podría haberse llevado a cabo, ni siquiera iniciado, sin tales medios técnicos ${ }^{13}$ :

«La idea de este Archivo fue iniciada hace años en el Centro de Estudios Históricos por D. Ramón Menéndez Pidal, quien al efecto hizo adquirir un fonógrafo Edison para registrar inscripciones en grandes cilindros de cera, análogos a los usados con este mismo objeto en el 'Phonogrammarchiv' del Instituto de Psicología de Berlín y en el 'Musée de la Parole' de la Universidad de París. Aún antes de esto, sirviéndose de un fonógrafo más sencillo, el Sr. Menéndez Pidal había ya registrado diversos romances cantados en las provincias de Santander, Cáceres, Badajoz y Madrid. Por diversos motivos, el Centro, durante mucho tiempo, no pudo desarrollar la iniciativa del Sr. Menéndez Pidal.

Desde que el fonógrafo y el gramófono llegaron a ser aparatos bastante perfectos para recoger y reproducir el sonido se comprendió la utilidad de estos instrumentos como nuevo medio de investigación científica y como elemento de información para las gentes del futuro. Los primeros en dar forma al aprovechamiento de estos recursos fueron Siegmund Exner, fundador del 'Phonogrammarchiv' de la Academia de Ciencias de Viena, en 1899, y Azoulay, organizador del 'Musée de Phonetique' de la Sociedad de Antropología de París en 1900.

Poco después, en 1904, inició sus actividades el 'Phonogrammarchiv' del Instituto de Psicología de Berlín, que es hoy uno de los depósitos fonográficos que ha adquirido mayor importancia por la riqueza y variedad de sus materiales. En 1911 la Universidad de París fundó su 'Musée de la Parole' con el apoyo técnico y económico de la casa Pathé Frères. La 'Lautabteilung' de la Biblioteca Nacional de

13 Navarro Tomás, T. (1931), Archivo de la Palabra. Trabajos realizados en 1931, Madrid, Junta para Ampliación de Estudios; reproducido en ARCHIVO DE LA PALABRA (1998), Voces de la Edad de Plata, Amigos de la Residencia de Estudiantes, Madrid, pp. 129-130. El Archivo de la Palabra se inició cuando el Ministerio de Instrucción Pública, por disposición de 19 de noviembre de 1930 dada por el ministro Tormo, a propuesta del Director de Bellas Artes, Gómez Moreno, encomendó al Centro de Estudios Históricos la realización de trabajos necesarios para la organización de una colección fonográfica, asignándole a este fin una modesta subvención, con cargo a la cual se había hecho ya un breve viaje, en el que, bajo la dirección de Rafael Benedito, habían sido recogidas algunas canciones andaluzas transcritas a oído o con ayuda de un sencillo fonostilo. 
París es de 1920. Hay establecimientos análogos en varias otras ciudades alemanas, en Leyden (Holanda) y en Oslo (Noruega). Existe también, que sepamos, un centro semejante en Barnard College, Nueva York».

Antonio Quilis ha explicado cual era el estado en que se encontraba la fonética en España antes de que Menéndez Pidal y sus discípulos entrasen en el campo $^{14}$ :

«¿Cuál era la situación de la fonética española en aquel momento? Muy menesterosa; pues prácticamente no existía. En los finales decimonónicos, Fernando de Araujo publica una serie de artículos y notas en las dos revistas fonéticas más importantes de aquella época: Phonetische Studien y Le Maître Phonétique. La recopilación de estos trabajos dio lugar a sus Estudios de fonética castellana, publicados en Toledo en 1894. También Wulff se interesa en esta época por nuestra fonética dialectal y escribe su conocido trabajo, Un chapitre de phonétique avec une transcription d'un texte andalou, publicado en Estocolmo en 1889.

En los albores del siglo XX, tres filólogos allende nuestras fronteras, Colton, Josselyn y Lenz, intentan precisar los fundamentos de nuestra fonética con sus trabajos: La phonétique castillane, Études de phonétique espagnole, y los artículos que bajo el título «Chilenischen Studien» publicó el último en la citada revista Phonetische Studien, todos trabajos de observación o, mejor dicho, trabajos de oído.

La fonética, en la Europa de aquellos principios del siglo XX, era una disciplina muy importante: la evolución de las lenguas, los estudios comparativos buscando sus comunes orígenes, se basaban en la fonética. Había que establecer leyes y, al mismo tiempo, explicarlas razonablemente. La fonética cobra una importancia, en cierto modo, desmesurada. El positivismo, que infunde en todas las ciencias el rigor del análisis, de la demostración y, si es posible, de la experimentación, también influye en esta disciplina. Todo ello se refleja en la exactitud de las descripciones de Araujo, de Josselyn o de Colton, la ciencia fonética que está naciendo en aquel momento exige precisión, y precisión comprobada: de ahí el concepto de 'punto de articulación', tan querido en la época, y la precisión milimétrica de la abertura de los incisivos.».

Menéndez Pidal era consciente de sus limitaciones en el campo de la fonética experimental (después de los fonógrafos iniciales no dispuso más que de un sencillo quimógrafo que había adquirido en París Pedro Blanco, miembro del Museo Pedagógico de Madrid), especialmente después de un viaje dialectal que, acompañado de Navarro Tomás, Américo Castro, Federico de Onís y

14 QuiLis, A. (2002), «Un siglo de fonética experimental española: de Navarro Tomás a Zamora Vicente», en Al trasluz del idioma. Homenaje a Alonso Zamora Vicente, Madrid, Servicio de Publicaciones de la Universidad Antonio de Nebrija, pp. 49-71. 
Martínez Burgos, realizó en el verano de 1911 por Asturias, León, Zamora y Salamanca. ${ }^{15}$ «En esa excursión», señaló Zamora Vicente, «se vio claramente la necesidad de utilizar un instrumento, unas técnicas de análisis fonético que hiciesen válido para el estudio todo el material recogido» ${ }^{16}$.

Para remediar tal situación, Menéndez Pidal encargó a Navarro Tomás que ampliase estudios en centros de fonética experimental extranjeros, y durante dos años éste trabajó por Europa, relacionándose con, entre otros Maurice Grammont y Georges Millardet (en Montpellier) y Giulio Panconcelli-Calzia (Hamburgo). A su regreso incorporaría a la nueva filología española las técnicas que se estaban empleando ya en Europa.

\section{PENSIONADO EN EL EXTRANJERO}

Para cumplir con semejante fin, el 9 de febrero de 1912 Navarro Tomás presentó la siguiente solicitud a la Junta ${ }^{17}$ :

«Tomás Navarro Tomás, Doctor en Letras, oficial del Archivo Histórico Nacional, a V.E. respetuosamente expone:

Que tiene en preparación algunos estudios sobre dialectología española, los borradores de los cuales, con textos y apuntes y varios artículos publicados, acompañan a la presente instancia, y siéndole absolutamente indispensable el conocimiento de la fonética experimental para poder llevar a cabo dichos estudios de una manera científica.

15 El quimógrafo es un cilindro que gira envuelto en un papel tiznado, sobre el cual van trazando líneas una o varias agujas puestas en contacto con los órganos del habla del informante. La aguja conectada con la bocina bucal es la que reacciona a las oscilaciones de presión del aire espirado. La línea de la nariz se modifica con los sonidos nasales, y la línea de la laringe registra la vibración de las cuerdas vocales. Por consiguiente, el quimógrafo capta, en primer lugar, los hechos fisiológicos, pero también indirectamente los acústicos. Como se conoce la velocidad de rotación del cilindro, se puede averiguar el tono por el número de vibraciones de las cuerdas vocales por unidad de tiempo. Más información sobre estas cuestiones en SchUbiger, M. (1989), Introducción a la fonética, edición española preparada por FRANCISCO J. ZAMORA SALAMANCA Y MiCAELA CARRERA DE LA RED.

16 ZAMORA Vicente, A. (1979), «Tomás Navarro Tomás (1884-1979)», Boletín de la Real Academia Española 59; reproducido como ZAMORA VicenTE, A. (2007), «Tomás Navarro Tomás, por su último discípulo en España», en SALABERRIA (ed.) (2007), pp. 43-73; p. 49.

17 Archivo de la JAE, Residencia de Estudiantes, Madrid. Citada en SALABERría (ed.) (2007), p. 41. 
A V.E. suplica se sirva concederle una pensión de un año para asistir a las enseñanzas de fonética experimental que se dan en las universidades francesas de Grenoble y Montpellier y en las alemanas de Berlín, Halle y Hamburgo, dejando la determinación de la cuantía de la pensión al arbitrio de la Junta.

Gracia que espera merecer de V.E. cuya vida guarde Dios muchos años».

La pensión le fue concedida, y con ella recorrió, como veremos a continuación, algunos de los principales laboratorios de fonética experimental de Europa.

$\mathrm{Su}$ primer destino fue Montpellier, en Francia, donde trabajaban Grammont y Millardet. ${ }^{18}$ Desde allí escribía a Menéndez Pidal el 6 de diciembre de 1912 una carta en la que se ve con claridad el gran interés que tenía por los instrumentos necesarios para los estudios fonológicos:

«Querido D. Ramón: M. Grammont me ha dicho que podremos trabajar con el aparato dos o tres veces por semana, los paladares están terminados; ${ }^{19}$ yo tengo el mío; le he propuesto que hagamos algo sobre las vocales castellanas; él busca también algunos datos sobre la disimulación de consonantes, y espero que haremos de las dos cosas; en fin, yo voy recogiendo detalles interesantes para perfeccionar la marcha de nuestro aparato y me voy enterando de otros inconvenientes que nosotros no resolvíamos ni aquí tampoco los resuelven.

A primeros de año quiero salir de Montpellier y después de detenerme unos días en Grenoble antes de entrar inmediatamente en Alemania».

El 2 de enero de 1913, todavía desde Montpellier, informaba a Menéndez Pidal que «Grammont ha tenido la bondad de venir al laboratorio durante estas fiestas sólo por mí y hemos trabajado con el aparato y con el paladar

18 Grammont escribió, entre otras obras, un Traité pratique de prononciation française (París 1914) y un Traité de phonétique (París 1933), que Navarro Tomás citó en su Manual de entonación española (México 1966, tercera edición; primera edición en Estados Unidos), pp. 32 y 18.

19 El paladar artificial —utilizado por vez primera por Oacley Coles en 1871 para finalidades clínicas - era un instrumento esencial para estudiar los movimientos de la lengua. Se utilizaba de dos maneras: se podía recubrir la lengua de una sustancia oscura que en la articulación coloreaba el paladar en los puntos de contacto, lo que podía observarse y fotografiarse utilizando espejos; o bien se introducía en la boca de los informantes una pequeña plancha espolvoreada de talco; al producir el sujeto sus articulaciones, la lengua quitaba el polvo de aquellos puntos en contacto, reapareciendo entonces el fondo de la planchita, que al ser sacada de la boca y dibujada en proyecciones o fotografiada mostraba la imagen de la articulación. Entre los que utilizaron este instrumento se encuentran investigadores como Grützner, Gutzmann, Kingsely, Rousselot, Montalbeti o Poirot, algunos de los cuales visitó TNT durante el disfrute de la pensión a la que me estoy refiriendo. 
artificial». Es interesante también citar lo que decía acerca de los trabajos que sobre un atlas lingüísticos estaban realizando allí, ya que, como es bien sabido, la confección de una Atlas Lingüístico de la Península Ibérica fue una de las empresas que con más ahínco persiguió TNT a lo largo de su vida: «He hablado mucho con Millardet sobre el Atlas y sobre su Atlas; con una amabilidad inagotable me ha explicado extensamente su método, y me ha enseñado sus borradores, planos, cuadernos, cuestionarios, etc.; he tomado notas de todo, sobre las cuales hablaremos nosotros después; son noticias muy útiles y de un gran valor para evitar errores, pérdidas de tiempo y mil otros inconvenientes».

El 1 de febrero continuaba en Montpellier y desde allí volvía a escribir a su maestro una carta en la que se encuentra una espléndida manifestación de la esencia de la fonética experimental y de su relación con las ciencias naturales:

«Querido D. Ramón: Verá V. porque me encuentro aún en Montpellier.

Para hacer un ensayo sobre las vocales españolas me señalé un pequeño programa: $1^{\circ}$ Las vocales consideradas en los órganos de la voz; trabajo de la laringe para cada una de ellas; posición de los labios y de la lengua; separación de las mandíbulas; manera de determinar el punto de articulación. $2^{\circ}$ Las vocales como sonidos, no como función fisiológica sino como resultado fonético de esa función; altura musical, cantidad, intensidad y timbre; manera de estudiar las vocales bajo cada uno de estos aspectos.

Una de las cosas que aquí he aprendido es la aplicación de la fonética experimental al estudio del ritmo y entonación del lenguaje; la idea que V. me anunció sobre el tonillo provinciano me afirmó en el interés que esto había empezado a despertarme. Nuestros aparatos no sólo servirán para analizar la naturaleza de cada articulación, su cualidad característica de sonora o sorda, explosiva o continua, palatal, labial, etc.; servirán también para determinar el contenido musical de esas articulaciones señalando los principios de ritmo y de armonía que dan a cada lenguaje una entonación particular.

Entre la voz hablada y la voz cantada no hay diferencia esencial; una de las cosas que con nuestros aparatos puede estudiarse es esa diferencia, y un día la estudiaremos: el lenguaje es una manera de hablar de canto que se ajusta a medidas de tiempo y de sonido más complejas que las que componen una canción. Los músicos dividen el sonido en tonos y semitonos: en el lenguaje hay que apreciar sonidos intermedios; dividen el tiempo matemáticamente en compases con 2/4, 3/4, 6/8, compasillo, etc., y emplean una infinidad de palabras sin significación exacta: lento, allegro, ritardando; todos estos matices pueden medirse en el lenguaje por centésimas y milésimas de segundo; los músicos indican la intensidad demasiado vagamente con las palabras, fuerte, piano, crescendo y hasta con signos: $<>$; en el lenguaje esta intensidad debe precisarse exactamente con arreglo a una escala de fuerza; la fonética, en fin, puede pautar una conversación o un discurso de manera más científica y más exacta que se pauta en música una canción. 
Una cosa es la función de los órganos que producen el sonido, y otra el sonido producido; la fonética experimental comprende estos dos aspectos, el primero como fonética fisiológica y el segundo como fonética musical; aún queda otro aspecto que debiera estudiar una fonética psicológica, acaso la más interesante de las tres; los músicos escriben de vez en cuando: dulce, expresivo, lánguido; ¿por qué no ha de llegar la fonética a estudiar también la expresión de las palabras, la relación entre el sonido y los sentimientos o las ideas? Como verá V. por todo esto, mis ideas sobre la aplicación de nuestro laboratorio y de todas nuestras herramientas han ensanchado un poco el horizonte; también han aumentado mis ganas de trabajar».

Hasta la primavera no se trasladó a Alemania, aunque antes, como veremos inmediatamente, pasó por Grenoble. El 12 de abril escribía de Menéndez Pidal desde Heidelberg:

«Querido D. Ramón: Hasta que no he estado en Alemania no me he creído en el extranjero; mi alemán me ha bastado para hacerme comprender; pero yo apenas cojo una palabra de lo que oigo; llegué a Heidelberg hace unos días; me he detenido en esta ciudad como podía haberlo hecho en cualquier otra sólo con el propósito de trabajar el alemán hasta poder comprender una explicación o una conferencia; estoy en una pensión de estudiantes alemanes; todas las horas las dedicó al alemán; ¿cuánto tiempo me costará estar en disposición de entender?; haré todo lo posible por que sea poco. La universidad está ahora en vacaciones; los cursos empiezan hacia el 25 de este mes; aquí no hay nada de fonética experimental, pero me presentaré al profesor de filología romana, y procuraré seguir sus cursos. Para habituar el oído aprovecho todas las ocasiones que puedo; he puesto un anuncio para cambiar lecciones.

Desde aquí escribiré a Schädel pidiéndole noticias para aprovechar bien el tiempo por estas universidades; él podrá decirme qué profesores debo visitar; además no dejaré de hablar con todos los profesores de filología por donde pase, para recoger sus indicaciones; este verano hay un curso interesante en Marburg; en él hay anunciadas varias conferencias sobre los diferentes métodos de la fonética, por Palconzelli [sic] Calzia del Instituto de Hamburg; de este es del único que habló Grammont; en Marburg está además Viëtor, y podré también seguir las conferencias».

Navarro Tomás mencionaba el nombre de Giulio Panconcelli-Calzia, con el que trabajaría, como veremos, en Hamburgo. También informaba que se había detenido en Grenoble unos días antes de viajar a Alemania: «le escribí a Blanco una carta sobre lo que he oído y he visto acerca del laboratorio de Rosset; mi opinión es que para estudiar y aprender algo a su lado hay que esperar a que él se desenrede del laberinto de sus reformas y publique algo que merezca la aprobación de los filólogos, sobre todo de los extranjeros, ya 
que los franceses parecen interesados en esa cuestión por cosas personales; yo creo que en su método y en sus aparatos hay muchas dificultades que él no ha podido vencer, por lo cual aún no ha publicado nada en donde se vean los resultados de sus experiencias. Hasta que él no vea claro no hay utilidad en seguir sus enseñanzas». Está claro porque no se detuvo más tiempo en Grenoble.

El 18 de junio seguía en Heidelberg y escribía a Menéndez Pidal informándole que:

«Apenas recibí la carta de V. envié a la Junta mi solicitud pidiendo cuatro meses de prórroga; con estos cuatro meses terminaría mi pensión en enero, en vez del próximo setiembre y yo podría arreglar el tiempo de este modo; julio y agosto en Marburgo

setiembre y octubre en Hamburgo

noviembre y diciembre en Leipzig y Halle

enero, para regresar, deteniéndome en París y Montpellier; en París quiero ver el laboratorio de Rousselot y hablar con Montalbety; si le parece a V. bien también podría presentarme a Gillieron para anunciarle nuestro Atlas y ver si me hace algunas indicaciones aprovechables. No sé si para el de Córcega seguirá el mismo plan que para el de Francia o lo habrá modificado mejorado con algunas modificaciones. Desde Leipzig a París, aunque con rodeo, podría pasar por Suiza para visitar a Gauchat.

En Heidelberg sólo estaré ya unos cuantos días (...) Lo que aquí he hecho ha sido principalmente aprender alemán. Cuando salí de Madrid apenas sabía un poco de gramática; en Montpellier no me fue posible dedicarle ningún tiempo; entré pues en Alemania sin saberlo, sin poder hablar más que algunas frases cortas y preparadas, y sin entender nada de lo que oía.

No podía hablar, no podía entenderme tampoco de lo que leía; en la pensión apenas podían comprenderme lo poco que hablaba; pasé un primer mes nervioso, disgustado de mí y arrepentidísimo de no haber aprendido antes el alemán. Millardet me había recomendado los cursos del profesor de filología Neumann, de esta universidad; empecé a seguirlos sin enterarme de lo que decía; al mismo tiempo me busqué un profesor; anuncié un cambio de lecciones — español alemán— para lo cual encontré un estudiante, y con todo esto he pasado dos meses, trabajando con poquísimo descanso y sin gran satisfacción, pues me parecía que no aprendía bastante aprisa y que este tiempo era un hurto que hacía en la pensión concedida.

En realidad he estado dentro de la pensión; he estudiado fonética, no sólo por lo que he podido coger de la Universidad, sino por los libros que empecé a leer apenas fui siendo capaz de entenderlos. Lehrbuch der Phonetik, de Gespersen, Grundfragen der Phonetik, del mismo y Grundzüge der Phonetik de Sievers me están introduciendo en la fonética, tal como aquí la estudian y me están preparando para poder aprovechar las lecciones y las conferencias, las conversaciones y visitas que vendrán de ahora en adelante; casi puede decirse que estas lecturas que aún 
continúo, y que continuarán con las de otros libros que me van dando a conocer, era una condición indispensable para seguir adelante en mi viaje.

Mis deseos de trabajar en la fonética castellana se van aumentando cada día conforme voy recogiendo preguntas y problemas referentes a estos estudios; tengo deseos de volver para poner esto en manos de $\mathrm{V}$. y ver cómo podemos trabajarlo. Espero poder contribuir a que el trabajo del Centro en el año próximo le deje a V. más satisfecho que el del presente».

De Heidelberg viajó, como señalaba en la carta anterior e indicó en la carta que se reproduce a continuación, a Marburgo, donde se encontró con Schädel, con Panconcelli-Calzia y con Wreder. No debió estar allí mucho tiempo ya que el 4 de agosto (1913) escribía Menéndez Pidal desde Hamburgo:20

«Querido D. Ramón: Llegó la carta de V. y se me admitió a trabajar en el Laboratorio. He encontrado además una pensión buena y barata. Estoy, pues, en buenas circunstancias para poder aprovechar aquí un poco tiempo.

El Laboratorio aquí me ha dejado admirado; hay en él todo lo que se puede desear, todos los aparatos de física, de medicina y puramente de fonética que suelen emplearse en este estudio. La instalación de muebles, electricidad, gas, agua, etc. está hecha con un gran sentido práctico y además con una riqueza casi suntuosa.

Aquí ha precedido el laboratorio a la fonética; tienen mucho dinero y todo lo compran; la ciudad quiere tener el mejor laboratorio del mundo; pero los aparatos muy limpios y brillantes, apenas salen de los estantes donde están ordenados y clasificados con cierta cosa de museo. No he sentido en estos días mucho ambiente de trabajo; el director tiene que recibir muchas visitas; otros dos o tres señores que trabajan no parecen poner mucho empuje. Yo por lo pronto puedo aprender mucho, sólo con ensayar el manejo y la aplicación de estos instrumentos. Más adelante podré saber mejor que ahora la clase de enseñanza científica que puedo recoger.

Tengo que dar a V. noticias de Schädel. Calzia me dijo en Marburg que la ciudad de Hamburg había dado a Schädel una subvención de 60.000 marcos para hacer el Atlas lingüístico de España. Esto viene de hace ya más de un año. Schädel ha hecho ya dos o tres viajes a España. ¿Estaba V. enterado de esto? ¿Contó Schädel con V. al proponerse este trabajo? Creo que no ha debido ser así puesto que no recuerdo haber oído a $\mathrm{V}$. nada de ello.

Antes de dar a V. esta noticia quise llegar a Hamburg para informarme mejor. Hay algo más, y es que la subvención ha sido aumentada, y Schädel se ha propuesto hacer también el Atlas hispano americano. El mismo día que llegué salió para la Argentina. Verá V. la noticia en el próximo boletín de la Revue de Dialectologie.

20 Antes, el 26 de julio escribió desde Marburgo a Menéndez Pidal, informándole de lo que había aprendido con Viëtor y Wreder sobre el Atlas Lingüístico. Esta carta se cita en PEDRAZUEla FuENTES, M. (2005), p. 275. 
Krüger, el que estuvo en Madrid, piensa que Schädel se ha propuesto una locura. Schädel conoce poco a España y apenas habla el castellano. Además ha perdido la amistad de todos los que han pasado por aquí. Riñó malamente con Griera, Barnils y Montolin; Rubio, que ha estado aquí de lector hasta ahora, acaba de marcharse y me ha contado mil historias; él también se ha peleado. Calzia mismo no le habla. Dice que he acertado en presentarme a él indirectamente sin buscar la recomendación de Schädel. Para ese Atlas monstruo no tiene ningún auxiliar; tiene su dinero, su cuestionario y su oído; a la fonética experimental no parece concederle importancia.

Según lo que me dicen, Schädel pasa aquí por un hombre sumamente audaz y ambicioso. Sea como quiera, el pensar que hayamos de recibir nuestro Atlas del extranjero me parece una afrenta. Y si Schädel no ha contado con V. ni siquiera para anunciarle su trabajo la cosa me parece aún más insoportable».

La elaboración de un Atlas Lingüístico de la Península Ibérica fue, como apuntaba antes, una de las empresas que con más ahínco y entusiasmo persiguió TNT a lo largo de su vida. Sin embargo, sólo llegó a publicarse, y en 1962, un primer tomo con 75 mapas, básicamente de fonética: Atlas Lingüistico de la Península Ibérica (Consejo Superior de Investigaciones Científicas), con Navarro Tomás como editor. ${ }^{21}$

La estancia en Hamburgo fue muy productiva. Allí aprendió más que en ningún otro lugar, y la relación que mantuvo con Panconcelli-Calzia especialmente interesante. De hecho, consultando algunas de las obras que Navarro escribió posteriormente se pueden encontrar referencias de éste fonetista. Así, en su Manual de pronunciación española se puede leer ${ }^{22}$ : «Los movimientos de las cuerdas vocales se estudian por medio del laringoscopio de García o el endoscopio de Flatau; las vibraciones vocálicas son demostrables al oído mediante el indicador laríngeo de Zünd-Burguet, y al tacto, tocando suavemente la garganta, a cada lado del tiroides, con las yemas de los dedos. Tapándose los oídos con las palmas de las manos se percibe también el fenómeno de la fonación como un rumor característico, que cesa al terminar las vibraciones de las cuerdas vocales. Para el estudio minucioso de las cualidades físicas de este fenómeno se utiliza principalmente la inscripción de la palabra por medio del fonógrafo, del gramófono o del quimógrafo. Sobre el

21 Sobre la historia de este proyecto, véase NAVARro TomÁs, T. (1975), «Noticia histórica del Atlas Lingüístico de la Península Ibérica», en Capítulos de Geografía Lingüística de la Península Ibérica, Bogota, Instituto Caro y Cuervo; reimpreso en SALABERria (ed.) (2007), pp. 141-159.

22 NAVArRo Tomás, T. (1965), Manual de pronunciación española (duodécima edición), Instituto Miguel de Cervantes, CSIC, p. 15. 
uso y manejo de estos aparatos véase G. Panconcelli-Calzia, Einführung in die angewandte Phonetik (Berlín, 1914)». Y en la Bibliografía también citaba de Calzia: Die experimentelle Phonetik in ihrer Anwendung auf die Sprachwissenschaft (Berlín 1924)23.

Continuando con la correspondencia Navarro Tomás-Menéndez Pidal durante la estancia como pensionado de la JAE del primero en Hamburgo, tenemos que el 11 de septiembre volvía a escribir a su maestro:

«Querido D. Ramón: Más adelante enviaré la lista de lo que sería necesario comprar antes de marcharme de aquí. Lo más caro será un aparato recién inventado para medir el acento musical, que simplifica y perfecciona notablemente el método seguido hasta aquí; cuesta 350 M., unas 500 pesetas, ¿será demasiado?, ¡en este laboratorio tienen ya cuatro ejemplares! El cilindro registrador que utiliza Calzia no es del mismo sistema que el de Rousselot; ${ }^{24}$ comparo uno y otro para cuando podamos comprar uno de ellos, pues con el que tenemos no estamos bien preparados; mejorándolo, servirá para viaje; estos no son más que para laboratorios; pero son de una perfección regular el movimiento y la velocidad que nunca podremos obtener del nuestro; el que tiene Grammont costó 1000 fr.; el de Calzia 1000 M.

Me disgusta lo poco que puedo aprender sobre experimentación ambulante; aún no sé de nadie que haya salido a los pueblos con los aparatos; Grammont no ha pensado nunca en sacar sus herramientas del laboratorio; Millardet hizo sus inscripciones en París; Rosset es un fonético, inventor, mecánico; Calzia es un investigador de laboratorio que no tiene experiencia de viajes; hasta ahora el más ambulante ha sido Josselyn, y sus libros italiano y español no están en el mejor concepto; dos estudios sobre dialectos italianos se están preparando sin salir del laboratorio de Hamburgo (...) El método que he visto hasta ahora seguido por todos es el que menos puede

23 Calzia dirigió desde 1914, junto a H. Gutzmann, la revista Vox (Berlín), continuación de Medizinisch-pëdagogische Monatscrift für die gesamte Sprachheilkunde, dirigida entre 1890 y 1914 por A. y H. Gutzmann.

24 Jean-Pierre Rousselot (1846-1924), fonético y dialectólogo francés, profesor en el Instituto Católico de París y en el Collège de France, que firmaba sus publicaciones bien como abbé Rousselot o como abbé P.-J. Rousselot, fue uno de los fundadores de la fonética experimental. Fue director entre 1899 y 1904 de la revista La Parole y de Revue de Phonétique —ambas de París - entre 1911 y 1914, y autor de una obra fundamental, Principes de phonétique experiméntale (París, 1897-1908), que Navarro Tomás citó en la bibliografía de su Manual de pronunciación española, antes citado: NAVARRo TOMÁs (1965), p. 33. En su Manual de entonación española (México 1966, tercera edición; primera edición en Estados Unidos), p. 22, Navarro Tomás escribía: «Rousselot, en sus primeros trabajos, encontró que sus vocales francesas presentaban indistintamente la misma altura, pero insistiendo más tarde en sus experiencias creyó hallar que a cada vocal correspondía un tono diferente [P. J. Rousselot, Les modifications phonétiques (París, 1891), p. 140, y «La parole étudiée avec un larynx artificiel»», en La Parole, París 1902, III, 65]». 
ayudar a nuestros propósitos; se utiliza el gas, la electricidad, los Rayos X, aparatos grandes, pesados; los constructores no han pensado en algo ligero, montable y desmontable, para viaje; los fonéticos no se lo han pedido. La causa debe estar en que los que estudian fonética experimental no son dialectólogos y los que estudian dialectología no son fonéticos; la única tentativa de enlace ha sido la de Millardet que ha juntado los dos aspectos, pero sin fundirlos. Nosotros vamos a hacer todo lo posible para llevar nuestro laboratorio a las aldeas; pero vamos a ser los primeros y vamos a tener que resolver por nuestra cuenta muchas dificultades. El seminario de Schädel y el laboratorio de fonética están a un quilómetro de distancia; los trabajos de uno y otro están aún mucho más separados. Schädel, Salow y Krüger no utilizan ni conocen el método experimental; todos sus trabajos son de oído; Schädel se ha marchado a recoger materiales para su Atlas sin el menor utensilio de experimentación; y no es que prescinda de ellos por una razón crítica, sino sencillamente porque nunca los ha tratado ni ha puesto el deseo o interés que $\mathrm{V}$. viene poniendo desde hace años en asociarse a la investigación dialectal (...)»

«Nosotros», decía, «vamos a hacer todo lo posible para llevar nuestro laboratorio a las aldeas; pero vamos a ser los primeros y vamos a tener que resolver por nuestra cuenta muchas dificultades». A más de uno le resonarán familiares estas palabras, como si fueran eco de las Misiones Pedagógicas que tanto se esforzaron por llevar la cultura a la España rural de aquella época.

El 12 de octubre, TNT enviaba a don Ramón «una lista de los aparatos y herramientas que más falta nos harán en nuestro laboratorio. Con ellos y con los que ya tenemos cogeremos tres puntos principales del lenguaje: la articulación, la cantidad y la entonación musical». ${ }^{25} \mathrm{Y}$ continuaba:

«La fonética, después de haberse dedicado casi exclusivamente al estudio fisiológico del lenguaje empieza a dar extraordinaria importancia a su naturaleza acústica; los psicólogos, como Krüger y Sievers reclaman materiales sobre ritmo, melodía, intensidad y sobre todo aquello por donde mejor se trasluzcan en el lenguaje los sentimientos y el carácter de las personas. La fonética puede proporcionar científicamente estos materiales; sobre el uso que hagan de ellos las gentes de fantasía ya es otra cuestión.

La nueva dirección interesa a las gentes más que la antigua; hay aquí un señor que estudia dialectos africanos sólo bajo el punto de vista rítmico, y lo veo además en otros principiantes que se interesan por la melodía de la frase más que sobre la naturaleza de las articulaciones; Calzia dice que la fonética se acerca a la ciencia del lenguaje por este camino más que señalando las diferentes variantes de $b, d$, $s$, etc. que puede haber entre los idiomas. Calzia no es un filólogo y le falta por consiguiente el cariño a la historia. De todos modos da al estudio fisiológico un valor fundamental.

25 Desgraciadamente, esta lista parece haberse perdido. 
Tendremos muchas cosas que hacer; cuando hablemos contaré a V. el plan tal como yo lo imagino; lo modificaremos, naturalmente, todo lo que sea necesario.

Aparatos para la intensidad y para el timbre no he señalado en la lista; no hay nada en lo cual se tenga confianza; se trabaja con empuje para encontrar mejores procedimientos; esperaré a hablar de nuevo con Grammont para ver qué resultados obtuvo de sus trabajos; mientras no haya algo definitivo sería emplear mal el dinero.

Pienso estar en Hamburgo hasta mediados de noviembre; conozco prácticamente los aparatos que van propuestos, pero siempre será mejor que yo mismo los compre y los ensaye antes de ponerlos en camino.

Ya entrenado y poseído del laboratorio como estoy aquí me parece que aprovecho mejor el tiempo que trasladándome a Halle donde está Krüger; me dice que en aparatos no encontraré en Alemania nada que no esté aquí, y en esto seguramente tiene razón. Krüger además como médico y como psicólogo estará demasiado lejos de lo que conviene a mi preparación.

No obstante quiero verle, aunque no sé cómo arreglarme. Después de Hamburgo me quedan tres puntos de parada: Zúrich por Gauchat, París por Gilliéron y Rousselot y Montpellier por Grammont (...)»

Un mes después, el 14 de noviembre, Navarro informaba a don Ramón que «la Junta me envía 500 marcos para comprar los aparatos que en mi lista proponía; no es la Junta si no $\mathrm{V}$. personalmente, que me da una prueba más de confianza en mi trabajo y continúa siempre facilitándome el camino para que llegue a hacer algo provechoso; con mi pensión y con este dinero, con la prórroga concedida, recomendaciones, etc., veo bien hasta donde será mi compromiso con el estudio de la fonética; ya veremos si sé corresponder; por falta de voluntad no ha de quedar». Señalaba, además, que «pensaba volver para fin de año, pasar la Navidad con mi familia y empezar el año en Madrid. Mi pensión, con la prórroga concedida y con un mes de equivocación, alcanza hasta el 24 de febrero. ¿Debo prescindir de estos dos meses? ¿No serán más útiles pasándolos aquí? Conforme pasan los días trabajo con más facilidad y provecho; creo que no debo renunciar a este tiempo a no ser que los planes de V. requieran lo contrario. Mi trabajo es ahora más con los libros que con los aparatos; revistas, libros, bibliografía, cosas que en Madrid sería difícil de encontrar».

El 17 de noviembre, Navarro volvía a escribir a Menéndez Pidal, deteniéndose esta vez con una invitación que se hacía a éste para asistir a un futuro congreso:

«Querido D. Ramón: Por mi carta que se ha cruzado con la suya sabe V. ya que la Junta me ha enviado el dinero; he hablado con el dueño de la casa constructora del aparato de Meyer; tienen que construirlo expresamente; lo harán con tiempo suficiente para que pueda estar en Madrid para mi regreso. 
Recibirá V. o habrá ya recibido una invitación de Meinhoff y Calzia para representar a España en el primer congreso de fonética experimental que quieren celebrar en Hamburgo; es reunión de filólogos y fonéticos: Morf, Gauchat, Scripture; ${ }^{26}$ de Francia invitan a Rousselot y Brundt; el hecho aún no es público aquí; esperan saber la inclinación de la acogida con que reciban Vds. la noticia. La cosa es principalmente de Calzia que es un hombre muy congresista.

La principal utilidad que podría resultar de esa asamblea podría ser que los filólogos hicieran comprender a los fonéticos especialistas la necesidad urgente de proporcionar medios experimentales a la investigación dialectal. En Gauchat y en Jud he leído ya esta petición; los inventores y constructores no se han preocupado de ello. Es verdad que hasta hoy la fonética tiene pocos aparatos propios; fuera del cilindro registrador, de formas más o menos diferentes, casi todo lo que hay en estos grandes laboratorios son aparatos tomados de la física; todo grande, pesado, intrasportable. No puede V. suponer cuánto me preocupo de esta cuestión; pero por más que pienso, busco y pregunto nadie me da idea útil: lo único práctico, con todos sus inconvenientes, es el paladar artificial. No ha habido nadie que haya salido con los aparatos a los pueblos. Nosotros saldremos!

He hablado con el constructor de la posibilidad de una maleta o estuche de viaje con un kymógrafo, un diapasón, laringógrafo, chismes para paladares, papel, barniz y hasta un fonógrafo, todo pequeño, recogido, ligero y fuerte, capaz de resistir traqueos y empujones. Este hombre, que trabaja mucho para cosas de fonética, ha oído con interés, ha comprendido y parece que se preocupará de ello. Esperan el congreso para ver la luz que sale de sus discusiones sobre este punto. Entre tanto no espere V. que yo pueda llevar nada especial. Nos arreglaremos con nuestros propios medios...»

\section{Y once días después, el 28 de noviembre, continuaba:}

«Querido D. Ramón: He recibido su tarjeta a la cual contesto lo más pronto posible para decir a V. algo sobre el congreso; Calzia parece esperar, ya con cierta impaciencia por V. y por otros. ${ }^{27}$

Los indicaciones que V. me pide serán principalmente sobre el carácter del congreso, sus planes y sus preparativos. Como su realización depende de la contestación de los invitados, aún no se da por absolutamente seguro, y por consiguiente se habla poco de él; lo primero ha sido invitar, después se solicitará el apoyo económico de la ciudad, se hará el programa de sesiones, visitas, agasajos, etc...

Según me dijo Calzia ayer, han contestado afirmativamente Gauchat, Morf, Viëtor, Gutzmann, Gradenigo y algún otro que no recuerdo; la parte francesa es la más dudosa: Calzia da por seguro que Rousselot no vendrá a causa de las rencillas personales que ha habido entre ellos; la ausencia de Rousselot, el fundador de la fo-

26 Entre las obras de E. W. Scripture se encuentra unos Elements of Experimental Phonetic (Nueva York 1902), que Navarro Tomás citó en la bibliografía de su Manual de pronunciación española, duodécima edición, CSIC, Madrid 1965), p. 33.

27 No he podido averiguar si finalmente este congreso se celebró. 
nética experimental, es una falta grave. Grammont no está invitado y tampoco Rosset, Poirot, Roudet, Chlumsky, Günd-Bouguet, Popovici, Joncelyn, etc; es decir, que falta principalmente la gente del oficio y en particular la de Francia, que es en realidad donde más hay, aunque no todos sean lumbreras. Por causa de la revista de Rousselot y la revista de Calzia, el laboratorio de aquí y de allá, hay rivalidades y envidias, y las personas no alternan ni se tratan. El congreso, por consiguiente, se celebrará a disgusto de la escuela de Rousselot, que además acaso lo considere como una usurpación de derechos, dada la reconocida filiación francesa de esta ciencia.

En el proyecto del congreso va mezclado lo científico y lo no científico. El dar a VV. la ocasión para que se encuentren, cambien impresiones, presenten problemas y den dirección y materiales a la fonética experimental no puede sino ser muy provechoso y de muy buenos resultados; y aún sería mucho mejor si los fonéticos especialistas, aunque de segunda o tercera fila, se encontrasen presentes para recoger esas impresiones y preocuparse de ellas. De esta asamblea es posible que saliesen buenas relaciones entre fonéticos y filólogos, y aun entre los mismos fonéticos, que andan, por cierto, desperdigados y reñidos científica y personalmente. He hablado de la omisión de los experimentales; también la escuela antigua, la descriptiva, está excluida, con excepción de Viëtor; Jespersen, Sievers, Passy, etc., no están invitados; estos hicieron declaraciones en sus escritos, hace ya tiempo, contra la 'Maschinenphonetik', y Calzia aún les guarda rencor. En fin, como V. ve, la idea de reconciliación no ha sido la que más se ha tenido en cuenta.

Lo que existe realmente, sin ser un exceso de mi malicia, es el afán de darse importancia y adquirir renombre, esta enfermedad que está volviendo loco al mundo. El laboratorio es un verdadero museo; cada día aumentan los aparatos y los muebles, todo hermoso y flamante; pero en el momento, cada cosa recibe su puesto y su número en un estante, en un estuche, entre cristales, y allí queda para que la gente lo vea y lo admire. Hay más movimiento de visitantes de paso que de trabajadores, y hasta hay cierta malquerencia contra éstos, entre el personal subalterno (no de parte de Calzia) por el temor al desorden, a las manchas y al polvo; artículos, fotografías, noticias en los periódicos, conferencias con proyecciones y demás frioleras son siempre cosas bien recibidas. Personalmente tengo que reconocer muchas consideraciones, toda clase de libertad y de buen interés, buena acogida, ayuda y consejos; solamente a V. debo contarle el flaco de las personas y de las cosas que dan idea de las dificultades con que un estudiante va formando su educación. Además esto pone a V. en antecedentes sobre el congreso, desconocidos seguramente para la mayor parte de los invitados.

Sólo el hecho de que V. vea personalmente el laboratorio, aunque sólo sea en una visita, es suficiente para que yo desee que V. venga; además, por lo que podría V. hacer sobre Atlas lingüístico completando los vacíos de mis observaciones que para ese tiempo ya le serán conocidas. Este debería ser el primer problema del congreso: 'la fonética experimental aplicada al estudio de los dialectos; qué es lo que los aparatos pueden estudiar y cómo lo pueden estudiar por valles y montañas'.

Mi regreso sería antes de que $\mathrm{V}$. viniese; aún tendría tiempo de preparar algo si no preparase V. antes otra cosa. Además es posible que no todos los que acepten 
vengan, por unas razones u otras de últimas hora. ¿No estará Morf para ese tiempo en España? Y sin embargo dio su consentimiento a la invitación.

Suyo aff ${ }^{\mathrm{mo}} . »$

Todavía se conserva una última carta, datada el 19 de diciembre, también desde Hamburgo. La mayor parte de ella trata de artículos y libros. Únicamente citaré uno de sus últimos pasajes: «Yo saldré de aquí a primeros de año; estaré una semana en Berlín y otra en Leipzig en donde visitaré los laboratorios de Gutzmann y Sievers. Después iré a Zúrich para ver el Atlas de Gauchat, y después a París. Todo esto hará unas cinco semanas. Desde París iré a Montpellier. A mediados de febrero estaré con mi familia, y el mes de marzo lo empezaré en Madrid».

Terminaba de esta manera una periodo vital para la formación de Tomás Navarro Tomás y para la introducción en España de la fonética experimental, de la que posteriormente tanto se beneficiarían el Atlas Histórico de la Península Ibérica y El Archivo de la Palabra. 